Review

\title{
Differences in the efficacy and safety among inhaled corticosteroids (ICS)/long-acting beta2-agonists (LABA) combinations in the treatment of chronic obstructive pulmonary disease (COPD): Role of ICS
}

\author{
M. Latorre a , F. Novelli a , B. Vagaggini ${ }^{\text {a }}$, F. Braido ${ }^{\text {b }}$, A. Papi ${ }^{\text {c }}$, A. Sanduzzi ${ }^{\text {d, P. Santus }}{ }^{\text {e, }}$ \\ N. Scichilone ${ }^{\text {f }}$, P. Paggiaro ${ }^{a, *}$ \\ ${ }^{\text {a } C a r d i o-T h o r a c i c ~ a n d ~ V a s c u l a r ~ D e p a r t m e n t, ~ P a t h o p h y s i o l o g y ~ U n i t, ~ U n i v e r s i t y ~ o f ~ P i s a, ~ I t a l y ~}$ \\ ${ }^{\mathrm{b}}$ Allergy and Respiratory Diseases Clinic, DIMI, University of Genoa, IRCS AOU San Martino-IST, Genoa, Italy \\ ${ }^{\mathrm{c}}$ Respiratory Medicine, Department of Medical Sciences, University of Ferrara, Ferrara, Italy \\ d Section of Respiratory Diseases, Department of Surgery and Clinical Medicine, University of Naples, Italy \\ e Dipartimento di Scienze della Salute, Pneumologia Riabilitativa Fondazione Salvatore Maugeri, Istituto Scientifico di Milano-IRCCS. \\ Università degli Studi di Milano, Italy \\ ${ }_{\mathrm{f}}^{\mathrm{f}}$ Department of Internal Medicine, Section of Pulmonology (DIBIMIS), University of Palermo, Palermo, Italy
}

\section{A R T I C L E I N F O}

\section{Article history:}

Received 4 July 2014

Received in revised form

28 October 2014

Accepted 30 October 2014

Available online 6 November 2014

\section{Keywords:}

COPD

Fluticasone

Budesonide

Pneumonia

\begin{abstract}
A B S T R A C T
Inhaled corticosteroids (ICS) are frequently recommended for the treatment of asthma and COPD, often in combination with long-acting beta2-agonists (LABA), depending on the severity of the disease and/or on the specific phenotype. Several ICS/LABA combinations are currently available that differ in their pharmacokinetic characteristics and dose of both components. Thus, this review assesses differences in the efficacy and the safety profiles of the ICS components in the two more frequently used ICS/LABA combinations (budesonide/formoterol and fluticasone/salmeterol) for the management of COPD.

Whereas the basic mechanism of action is similar for all ICS (binding with the intracellular glucocorticoid receptor, which mediates both genomic and non genomic effects), the pharmacokinetic and characteristics of ICS are quite different in terms of receptor affinity, bioavailability, lipophilicity and drug persistence in the airways. Fluticasone persists longer in airway mucus and requires more time to dissolve in the lining fluid and then enter the airway wall, whereas budesonide is cleared more quickly from the airways.

Comparative efficacy of the two major ICS/LABA combinations recommended for the treatment of COPD show similar efficacy in terms of reduction of exacerbations, improvement in forced expiratory volume in the first second (FEV1) and quality of life. One retrospective cohort study suggested a greater efficacy for the budesonide/formoterol combination on hospital or emergency department admissions, oral corticosteroid courses, and addition of tiotropium, and an observational real-life study reported a greater reduction of COPD exacerbations with budesonide/formoterol than with fluticasom/salmeterol combination.

Among the potential side effects of chronic ICS treatment in patients with COPD, recently the use of fluticasone or fluticasone/salmeterol combination has been associated with a higher prevalence of pneumonia in the major long-term studies. On the other hand, no similar increased risk of pneumonia has been reported in patients with COPD treated with the budesonide/formoterol combination. A recent population-based cohort study from the Quebec database showed that the adjusted odds ratio for having severe pneumonia was higher for fluticasone (2.1) than for budesonide (1.17) or other ICS (1.41). Of the ICS studied, only fluticasone demonstrated a dose-related increase in risk of pneumonia in patients with COPD. This difference between fluticasone and budesonide may be explained by the longer retention of fluticasone in the airways, with potentially greater inhibition of type- 1 innate immunity.

Therefore, the risk:benefit ratio should be evaluated thoroughly when choosing an ICS/LABA combination for patients with COPD.
\end{abstract}

(ㄷ) 2014 Published by Elsevier Ltd.

\footnotetext{
* Corresponding author. Cardio-Thoracic and Vascular Department, University Hospital of Pisa, Via Paradisa 2, 56124 Pisa, Italy. Tel.: +39 050995365 ; fax: +39 050580124. E-mail address: pierluigi.paggiaro@unipi.it (P. Paggiaro).
} 


\section{Introduction}

Asthma and chronic obstructive pulmonary disease (COPD) are major diseases, both in terms of their prevalence in the general population and the associated socio-economic burden. Those are characterized by variable degrees of airway obstruction, and the two diseases involve underlying inflammation of the bronchial wall and lung parenchyma that differ in terms of their characteristics and response to treatment.

Inhaled corticosteroids (ICS) are the most effective antiinflammatory agents used to treat airway diseases, because of their role in modifying several inflammatory cells and pathways involved in asthma and COPD [1]. In asthma, ICS are the cornerstone of pharmacologic treatment, and are recommended in all symptomatic patients, at doses that differ depending on disease severity, as monotherapy or in combination with long-acting beta2agonists (LABA) or leukotriene receptor antagonists [2]. In COPD, ICS represent a second step treatment, and those are in general recommended in more severe patients (FEV $1 \leq 50 \%$ of predicted), who remain symptomatic despite long-acting bronchodilator treatment, and/or patients with frequent exacerbations [3]. Recently, a special clinical and functional situation, characterized by features typical of both asthma and COPD (asthma-COPD overlap syndrome, ACOS) has been described and well characterized in terms of diagnosis and treatment; ICS, together with long-acting bronchodilators, are recommended for treating these patients [4].

Currently, several ICS/LABA combinations are available: the older fluticasone propionate/salmeterol (FS) and budesonide/formoterol (BF) combinations, and the more recent beclometasone/ formoterol $(\mathrm{BDP} / \mathrm{F})$, fluticasone propionate/formoterol $(\mathrm{FF})$, and mometasone/formoterol (MF) combinations. While the first two combinations are indicated for treatment of both asthma and COPD, the others are now recommended only for treating asthma. Furthermore, also fluticasone furoate/vilanterol (FV) combination has been introduced on the market, with the indication for COPD treatment in US only, but very limited data are available with this combination.

Despite sharing a similar basic mechanism of action, ICS differ in terms of pharmacokinetic characteristics, and this may determine important difference in their efficacy and safety. Therefore, an important question is whether all ICS are equivalent in the management of airway diseases. Very few comparative studies have been conducted, and only indirect comparisons are available.

This review will attempt to understand if there are differences in the efficacy and in the safety profiles of the ICS included in the ICS/ LABA combinations currently used for the management of COPD. In particular, the aim of this review was to compare the two more frequently used ICS/LABA combinations in COPD patients (budesonide/formoterol and fluticasone/salmeterol) in terms of efficacy (reduction in the rate of exacerbations) and of safety, with special attention to the risk of pneumonia.

\section{Pharmacology of inhaled corticosteroids}

Corticosteroid (CS) effects on target cells are mediated by mechanisms that involve binding to DNA, or mechanisms that are independent of DNA binding [5]. The genomic effect of corticosteroids occurs through binding of the CS molecule to cytoplasmic glucocorticoid receptors (GR), after which the CS-GR complex enters the nucleus and interacts with specific steroid-responsive DNA sequences, leading to trans-activation of genes encoding transcription factors that promote the release of anti-inflammatory compounds (e.g., lipocortin) and to downregulate the release of pro-inflammatory cytokines. This activity of the CS-GR complex requires activation of histone-deacetylase (HDAC), which changes the local chromatin structure and de-represses transcription of nuclear sequences, allowing them to be transcribed. Whereas, the effect of CS independent of direct DNA binding is due to the ability of the CS-GR complex to bind certain signal-dependent transcription factors (e.g., nuclearfactorkB (NFkB), activator protein 1 (AP-1)) that are normally activated as a result of signal transduction cascades originating from the binding of circulating cytokines to specific cell receptors. Binding of these transcription factors by CSGR neutralises their ability to transactivate genes encoding proinflammatory molecules (trans-repression). The intrinsic binding activity of a CS for the GR is the main determinant of its efficacy for both of these mechanisms; however, other pharmacokinetic characteristics (e.g., solubility, retention in the cell, rate of inactivation) are also important.

In Table 1 are reassumed the pharmacokinetic and pharmacodynamic characteristics of the available ICS, data extensively reviewed elsewhere [6-9]. Binding affinity for the GR is particularly high for fluticasone and mometasone, followed by budesonide and by other ICS. Systemic bioavailability is negligible for fluticasone, mometasone and ciclesonide, but it is also low for budesonide, whereas it is high for beclometasone and flunisolide. The volume of distribution is large for fluticasone and ciclesonide, due to their high liposolubility, intermediate for budesonide, mometasone, and beclometasone, and low for flunisolide. The binding affinity, combined with the percent of lung delivery obtained with the various formulations (metered-dose inhalers, MDI, vs dry powder inhalers, DPI) available for the different compounds, allows calculation of the equivalent doses of each ICS. These data are available in several equivalence tables, for example, in the international GINA guidelines. For the most frequently used ICS (included in ICS/LABA combinations) for the treatment of asthma and COPD, $400 \mathrm{mcg}$ of beclometasone in a hydrofluoroalkane (HFA)-propelled pressurised metered-dose inhaler (pMDI) is equivalent to $800 \mathrm{mcg}$ of DPI budesonide and to $500 \mathrm{mcg}$ pMDI/DPI fluticasone [2].

Currently only fluticason/salmeterol and budesonid/formoterol combinations are licenced for the treatment of COPD, therefore, we will continue with a pharmacologic comparison of fluticasone and budesonide. As mentioned before, fluticasone has higher intrinsic affinity and lower systemic bioavailability than budesonide. However, the most important difference between these two compounds is the higher lipophilicity $(\log K)$ of fluticasone $(\log K=4.5)$ versus that for budesonide ( $\log K=3.7)$. This may explain the larger volume of distribution of fluticasone. Another important difference is

Table 1

Determinants of efficacy and therapeutic index in the different ICS (adapted with permission from Raissay et al. [6].

\begin{tabular}{lllll}
\hline & $\begin{array}{l}\text { Binding } \\
\text { affinity } \\
(\text { RRA })^{\mathrm{a}}\end{array}$ & $\begin{array}{l}\text { Oral } \\
\text { bioavailability } \\
(\%)\end{array}$ & $\begin{array}{l}\text { Systemic } \\
\text { clearance } \\
(L / h)\end{array}$ & $\begin{array}{l}\text { Volume of } \\
\text { distribution } \\
(L)\end{array}$ \\
\hline BDP MDI, 40 and $80 \mathrm{mcg}$ & 0.4 & 20 & 150 & 424 \\
BUD DPI, 90 and 180 mcg & 9.4 & 11 & 84 & 280 \\
CIC MDI, 80 and 160 mcg & 0.12 & $<1$ & 152 & 897 \\
FLU MDI, 80 mcg & 1.8 & 20 & 58 & 96 \\
FP MDI, 44, 110 and & 18 & $\leq 1$ & 66 & 602 \\
220 mcg & 18 & $\leq 1$ & 66 & 602 \\
FP DPI, 50, 100 and & & & & \\
250 mcg & 23 & $<1$ & 53 & 332 \\
MF DPI, 110 and 220 mcg
\end{tabular}

$\mathrm{BDP}=$ beclomethasonedipropionate; $\mathrm{BUD}=$ budesonide; $\mathrm{CIC}=$ ciclesonide; $\mathrm{FLU}=$ flunisolide; $\mathrm{FP}=$ fluticasone propionate; $\mathrm{MF}=$ mometasonefuroate; $\mathrm{MDI}=$ metered dose inhaler; DPI $=$ dry powder inhaler.

a Receptor binding affinities of ICSs relative to dexamethasone equal to 1 ; RRA: relative receptor affinity. 
in their lung retention times, which can be expressed by the area under the curve (AUC) of plasma concentrations obtained in the first hours of a single inhalation of ICS. This index of rapid systemic availability is lower in patients with airway obstruction (like patients with severe COPD) than in normal subjects, due to lower drug penetration and deposition in patients with high airway resistance. However, the AUC is consistently lower for fluticasone (1.50 and $0.84 \mu \mathrm{M} / \mathrm{h}$ in normal subjects and COPD patients respectively) than for budesonide (6.21 and $3.07 \mu \mathrm{M} / \mathrm{h}$, respectively) [10]. This may be explained by the consideration that inhaled fluticasone persists longer in the mucus and more time is required for dissolving in the lining fluid, and then for penetrating in the airway wall where it may exert its anti-inflammatory effect. Other data which support this explanation are the maximum concentration reached in the blood $\left(C_{\max }: 0.09\right.$ vs $1.08 \mu \mathrm{M}$, for fluticasone and budesonide respectively) and the time to maximum concentration ( $T_{\max }: 50.8$ vs $15.5 \mathrm{~min}$, respectively) after a single inhaled dose, so that the mean residence time (MRT) in the airways is higher for fluticasone than for budesonide (MRT: 12.8 vs $4.41 \mathrm{~h}$, respectively). This high lipophilicity of fluticasone may explain the high local activity and the long duration of action, whereas for budesonide the long duration of action (demonstrated in all clinical trials) may result from a different mechanism: active intracellular esterification and deposition, with subsequent prolonged release of the drug through lipolysis. Therefore, when sputum was collected in the first $6 \mathrm{~h}$ after a single administration of equivalent doses of fluticasone or budesonide, the sputum ICS concentration was 5-fold higher with fluticasone, although the cumulative sputum volume was similar [10]. This supports the contention that fluticasone persists longer than budesonide in the airways, and might explain the high efficacy of this drug on airway inflammation.

On the other hand, the more balanced lipophilic/hydrophilic characteristics of budesonide may explain its higher efficacy in terms of rapid onset of action, in part due to the strong nongenomic effects of budesonide. Several in vitro and in vivo experimental studies have confirmed that an anti-inflammatory effect of budesonide may be detected a few hours after administration $[11,12]$.

\section{Comparative clinical efficacy of fluticasone/salmeterol and budesonide/formoterol combinations in COPD}

While several randomized clinical trials (RCTs) in asthma have directly compared these two formulations, no such data have been reported for COPD. In asthma, budesonide/formoterol was demonstrated as effective as fluticasone/salmeterol when administered regularly at equivalent daily doses [13], while it resulted more effective than fixed higher dose fluticasone/salmeterol combination in improving lung function, quality of life, and in reducing the incidence of severe asthma exacerbations, hospitalization and emergency department, when used according to the maintenance and reliever strategy $[14,15]$.

In COPD, both fluticasone/salmeterol and budesonide/formoterol are thought to reduce exacerbations to a similar degree, but no double-blind prospective RCTs have compared exacerbation rates between these two combinations. Within the limits imposed by the difficulty of comparing studies conducted in different COPD populations, with different inclusion criteria, concomitant medications, duration of treatment and endpoints, it appears that the efficacy of these two combinations is similar. In the TRISTAN study Calverley et al. compared the effects of a combination therapy with salmeterol $50 \mu \mathrm{g}$ and fluticason propionate $500 \mu \mathrm{g}$ in a single device, with the individual component and placebo, for 12 months. All active treatments improved lung function, symptoms, health status and reduced frequency of exacerbations per patient year compared with placebo. Combination therapy was better than fluticasone propionate alone and salmeterol alone in terms of pre-treatment and post-bronchodilator FEV1 (the primary outcome) [16]. Similarly in the TORCH study, a randomized double-blind trial for a period of three years, the comparison between the combination treatment with salmeterol $(50 \mu \mathrm{g})$ and fluticasone $(500 \mu \mathrm{g})$ administered together in a single inhaler versus the individual components and placebo showed a significant reduction in the mean moderate-severe exacerbation rate per participant per year in favour of the all treatments when compared with placebo (exacerbation rate/pt/yr: salmeterol/fluticasone 0.85 , salmeterol 0.97 , fluticasone propionate 0.93 vs placebo: $1.13, p<0.001$ ) and a non significant reduction in exacerbation requiring hospitalization (exacerbation rate/pt/yr: salmeterol/fluticasone 0.16 salmeterol 0.16 , fluticasone propionate 0.17 vs placebo: 0.19 ). For lung function, the mean baseline FEV1 in the combination-therapy group increase of $0.029 \mathrm{~L}(L)$ a significant improvement versus placebo, salmeterol and fluticasone propionate $(-0.062(\mathrm{~L}),-0.021(\mathrm{~L}),-0.015(\mathrm{~L})$ respectively; $p<0.001)$ [17].

We can observe similar results also in the two studies conducted with the budesonide-formoterol combination. In a first study Calverley et al. observed a significant reduction in total number of annual exacerbation with budesonide/formoterol (320/9 $\mu$ g twice daily) vs PL (1.38 vs 1.80 ) and in patients treated with budesonide/ formoterol the persistence of the improvement in the FEV1 value obtained during the run-in period in which patients received oral prednisolone (30 mg) o.d. and inhaled formoterol; in contrast, FEV1 declined greatly and rapidly with all other treatments (budesonide $400 \mu \mathrm{g}$ end formoterol $9 \mu \mathrm{g}$ ) [18]. In the study of Szafranski et al. were confirmed similar results with a significant reduction in severe exacerbations in the group of patients treated with budesonide/formoterol vs formoterol $9 \mu \mathrm{g}$ and placebo (exacerbation rate: budesonide/formoterol 1.42; budesonide 1.59; formoterol: 1.89; placebo: 1.87). The FEV1 significantly improved in all groups of treatment [19]. A Cochrane Systematic review including five studies with FS and four with BF revealed a similar OR in favour of the two combinations vs LABA alone ( 0.77 vs 0.73 , respectively) in terms of reduction of exacerbation rates [20].

One propensity matched COPD cohort study of 1-year duration conducted in Canada suggested that differences in efficacy might exist between the ICS/LABA combinations in favour of budesonide/formoterol. From a large Canadian database, patients with a diagnosis of COPD who started treatment with a ICS/LABA combination (index date), were retrospectively followed for 1 year from the index date to assess the course of oral CS, emergency department (ED) access, hospital admission, or addition of tiotropium (all considered markers of uncontrolled disease). Patients who received budesonide/formoterol were compared with patients receiving fluticasone/salmeterol, after adjustment for variables that might indicate a different propensity to the prescription (e.g., age, COPD severity as assessed by previous hospitalization or course of oral CS). Therefore, 1131 patients with COPD who started treatment with budesonide/formoterol at the index date were compared with 1131 matched patients with COPD who started treatment with fluticasone/salmeterol. In the ensuing year, the odds ratio (OR) for course of oral CS (OR 0.85, 95\% confidence interval (CI): 0.72-1.0), ED access (OR 0.75, CI: 0.58-0-97, $p<0.05$ ), hospital admission (OR 0.61, CI: 0.47-0.81, $p<0.05$ ) and addition of tiotropium (OR $0.71, \mathrm{CI}: 0.57-0.89$ ) were all in favour of the budesonide/formoterol combination. Despite the limitations characteristic of observational studies and the risk of not having completely controlled for "bias by indication", these data suggest that in real life the budesonide/formoterol combination may be more effective that the fluticasone/salmeterol combination [21]. 
The results of the Canadian study have been recently confirmed by the PATHOS study. This was a population-based, retrospective, observational study on a large Swedish database, with the aim to evaluate the health resources of COPD patients treated with budesonide/formoterol or fluticasone/salmeterol combinations. Patients were matched according to the propensity score, thus making two comparable groups of more than 2700 patients each. The exacerbation rates in the budesonide/formoterol and fluticasone/salmeterol groups were 0.80 and 1.09 per patient-years, respectively ( $p<0.0001$ ), and yearly rates for COPD-related hospitalizations were 0.1 and 0.21 , respectively $(p<0.0001)$. All other healthcare outcome were also significantly reduced with budesonide/formoterol vs fluticasone/salmeterol combination [22,23]. Therefore, also this study suggests that long-term with budesonide/ formoterol combination was associated with fewer healthcare utilization-defined exacerbations than fluticasone/salmeterol combination in patients with moderate and severe COPD.

Recently, new ICS/LABA combinations have been studied in COPD. Fluticasone furoate/vilanterol is a new combination which may be used once daily. Some studies have demonstrated the efficacy and safety of this combination in comparison with monocomponents, on both pulmonary function and exacerbation rate [24-26]. In particular, in the two replicate 1-year studies, a pooled analysis demonstrated fewer moderate and severe exacerbations in all fluticasone/vilanterol groups (0.93-0.81 exac/pt/yr) in comparison with vilanterol alone (1.11 exac/pt/yr) [26]. The other new combination, beclometasone/formoterol combination in the extrafine formulation, has been demonstrated more effective that formoterol alone in reducing the rate of moderate and severe exacerbations (OR: 0.72, CI: 0.62-0.84) [27]. Because data on these new combinations are limited, they were not included in the overall evaluation of efficacy and safety of ICS/LABA combinations in COPD.

\section{Potential side effects of ICS in COPD: the risk of pneumonia}

Long-term treatment with ICS has been associated with some potential side effects in patients with COPD. The most frequently reported systemic side effects, apart from adrenocortical suppression, are osteoporosis, bone fractures, skin thinning and purpura. These events have been largely considered in several long-term studies on the efficacy of ICS alone or in combination with an LABA [17,28-31]. In general, there is consensus on some negative effects on bone turnover in subgroups of COPD patients receiving long-term treatment with high doses of ICS, but the risk of bone fractures is not higher in the total population of patients with COPD $[29,31]$. Skin bruising has been reported frequently in patients with COPD treated with high-dose ICS, but when this effect was corrected by the use of oral CS cycles, the effect was no longer significant $[30,31]$. Relatively infrequent side effects include glaucoma, cataracts, diabetes mellitus and weight gain; these side effects may occasionally be observed in COPD patients, but in general they do not represent serious adverse events [28]. More recently, great attention has been focused on the potential to increase the risk of pulmonary infections like pneumonia. This point is potentially important considering the well-known immunomodulatory effect of ICS.

In asthma, a recent meta-analysis of several long-term studies using inhaled budesonide, alone or in combination with formoterol, has revealed a reduced risk of pneumonia in COPD patients treated with ICS, while the risk of severe pneumonia (leading to hospitalization or death) was slightly but not significantly increased in all patients, particularly in adolescents and adults, and in women [32].

The TORCH study revealed an increased risk of pneumonia in COPD patients treated with fluticasone, alone and in combination with salmeterol [17]. A detailed subgroup analysis showed an increased risk of pneumonia fluticasone/salmeterol versus fluticasone (19.3\% and $18.3 \%$, respectively, $p<0.001$ ), but no increase in the risk of death from pneumonia, in patients taking fluticasone or fluticasone/salmeterol. The risk was higher in patients with more severe COPD, in particular in patients with GOLD stage 4 and in patients with Medical Research Council (MRC) dyspnoea scores of 4-5 [33,34]. In the INSPIRE study, a similarly increased risk of exacerbations treated with antibiotics was observed in patients treated with a fluticasone/salmeterol combination compared to patients treated with tiotropium (7.6\% vs 3.6\%, respectively, $p<0.008$ ) [35]; moreover, a one-year study comparingfluticasone/ salmeterol combination with fluticasone alone also showed similar results ( $4.5 \%$ vs $1.4 \%$ in FS and F respectively, $p<0.05$ ) [36]. A more detailed analysis of the TORCH and INSPIRE studies revealed an excess risk of 3.6 pneumonia events per 100 patients and of 5.7 events per 100 patients, respectively, corresponding to a number needed to treat (NNT) of 28 and 18 patients, in patients treated with fluticasone.

In contrast, a similar risk of pneumonia has not been reported in patients with COPD receiving budesonide/formoterol. A metaanalysis of seven long-term studies with budesonide alone or with budesonide/formoterol combinations found an hazard ratio (HR) of 1.05 (CI: $0.81-1.37)$ for pneumonia-related adverse events in patients treated with budesonide [37]. The main results from the major long-term studies with fluticasone/salmeterol and budesonide/formoterol combinations on this point are summarised in Table 2.

A recent meta-analysis of the risk of pneumonia in patients with COPD treated with ICS included 17 studies with fluticasone or fluticasone/salmeterol, seven studies with budesonide or budesonide/ formoterol, and one study with mometasone; more than 20,000 patients with COPD were examined. The adjusted OR for pneumonia was 1.67 (CI: $1.47-1.89$ ) for fluticasone-treated patients $(p<0.0001), 1.19$ (CI: 0.92-1.53) for budesonide-treated patients (no significant), and 2.00 (CI: 0.83-4.81) for mometasone (not significant) [38]. This observation clearly demonstrates that fluticasone, but not budesonide (fewer data are available for other ICS including mometasone) are responsible for an increased risk of pneumonia; however this does not appear to translate into increased overall mortality.

More recently, an interesting population-based cohort study was conducted on the risk of pneumonia in patients with COPD treated with ICS [39]. Patients were identified from the Quebec database according to consumption of inhaled respiratory drugs (patients $>55 \mathrm{yrs}$ were included to minimize inclusion of asthmatics patients, in addition to the use of antileukotriene drugs). The index date was the time of the first ICS/LABA combination prescription, after which they were followed until the first occurrence of severe pneumonia (leading to hospitalization or death). Patients were matched with controls by age and COPD severity, determined by drug and health resource consumption. ICS dosage was recorded. The adjusted OR for severe pneumonia was higher for fluticasone (2.1) than for budesonide (1.17) or other ICS (1.41). There was also a clear dose response curve with fluticasone (OR increasing from 1.46 with low dose to 2.21 with high dose) but not with budesonide (OR 1.05 with low dose and 1.13 with high dose). This was clear from differences in dose-dependent curves of the risk of severe pneumonia for patients with COPD receiving fluticasone or budesonide (Fig. 1).

Also the previously mentioned PATHOS study supported this observation [23]. Compared with budesonide/formoterol combination, rate of pneumonia and admission to hospital were higher in patients treated with fluticasone/salmeterol combination, with a rate ratio 1.73 (CI: $1.57-1.90 ; P<0.001)$ and $1.74(1.56-1.94$; $P<0.001)$, respectively. The pneumonia event rate per 100 patient 
years for fluticasone/salmeterol combination versus budesonide/ formoterol combination was $11.0(10.4-11.8)$ versus $6.4(6.0-6.9)$ and the rate of admission to hospital was 7.4 (6.9-8.0) versus 4.3 (3.9-4.6). The mean duration of admissions related to pneumonia was similar for both groups, but mortality related to pneumonia was higher in the fluticasone/salmeterol group (97 deaths) than in the budesonide/formoterol group (52 deaths) (hazard ratio 1.76, 1.22 to $2.53 ; P=0.003$ ). All cause mortality did not differ between the treatments $(1.08,0.93$ to $1.14 ; P=0.59)$.

In the two replicate 1-year studies comparing fluticasone furoate/vilanterol with vilanterol alone in COPD patients, all groups treated with fluticasone/vilanterol showed a higher prevalence of pneumonia (5.9-6.8\%) than vilanterol group (3.3\%) [26], confirming the higher risk of fluticasone in favouring non fatal pneumonia. This is in agreement with the further higher retention time in the airways of fluticasone furoate in comparison with fluticasone propionate [40].

The mechanism by which fluticasone increases the risk of pneumonia at the doses used in clinical trials, while reducing the total number and severity of exacerbations, is not obvious. A hypothesis has been proposed, based primarily on the observation that pneumonia often occurs in the weeks following an unresolved exacerbation [41]. Patients with COPD often have a spectrum of pathogens colonising the lower airways. Whereas the incidence of de novo pneumonia not preceded by exacerbation of symptoms is not greatly increased by ICS use, protracted unresolved infective exacerbations are associated with a $70 \%$ increase in the risk of pneumonia. This is likely because the airway infections responsible for the exacerbation, and the consequent airway inflammation, are not adequately controlled by the innate immune system and the ICS treatment, thus allowing infection/inflammation to penetrate to alveoli and pleural space. While all ICS can suppress local innate immunity, immunosuppression with fluticasone against pneumonia pathogens has been demonstrated [42]. This may be explained by the high lipophilicity of fluticasone mentioned above, which results in a high retention time in the mucus and therefore higher airway concentrations than ICS like budesonide [10]. In an experimental model, the inhibition of human alveolar macrophage function occurred at much lower concentrations of fluticasone than budesonide [43]. In effect, human phagocytic cells initiate type-1 immune responses on exposure to a bacterial (LPS) challenge in the lower airway spaces, and this immediate response includes an increase in Th1 cytokines like IL-6 and TNF-alfa. For these two cytokines, fluticasone was 10 -fold more potent that budesonide at

Table 2

Main efficacy results on some endpoints and the risk of pneumonia in COPD patients treated with FS or BF combinations, in the major RCTs of 1 year at least duration.

\begin{tabular}{|c|c|c|c|c|c|}
\hline & Treatment ( $\mu \mathrm{g} / \mathrm{bid})$ & $\begin{array}{l}\text { Reduction of } \\
\text { exacerbations rate }\end{array}$ & Improvement in FEV1 & $\begin{array}{l}\text { Improvement in qol } \\
\text { (evaluated by SGRQ) }\end{array}$ & $\begin{array}{l}\text { Risk of pneumonia } \\
\text { (\% of patients with } \\
\text { pneumonia during treatment) }\end{array}$ \\
\hline \multirow[t]{2}{*}{$\begin{array}{l}\text { Calverley et al., } \\
2003 \text { TRISTAN study, } \\
1 \text { year duration (13) }\end{array}$} & SFC $50 / 250$ vs PL & $35 \%$ (total exacerbations) & $\begin{array}{l}0.132 \mathrm{~L}(0.105-0.161) \\
P<0.0001 \\
\text { Pre-bronc FEV1 }\end{array}$ & $\begin{array}{l}-2.2(-3.3 \text { to }-1.0) \\
P<0.0005^{\mathrm{b}}\end{array}$ & \multirow[t]{2}{*}{ No data } \\
\hline & SFC $50 / 250$ vs SAL 50 & 4\% (total exacerbations) & $\begin{array}{l}0.095 \text { L }(0.067-0.122) \\
P<0.0001 \\
\text { Pre-bronc FEV1 } \\
0.073 \text { L }(0.046-0.101) \\
P<0.0001 \\
\text { Pre-bronc FEV1 }\end{array}$ & $\begin{array}{l}-1.4(-2.5 \text { to }-0.2) \\
P<0.05^{\mathrm{b}} \\
-1.1(-2.2 \text { to }-0.1) \\
P=0.07^{\mathrm{b}}\end{array}$ & \\
\hline $\begin{array}{l}\text { Calverley et al., } 2007 \\
\text { THORC study, }\end{array}$ & SFC $50 / 250$ vs PL & $\begin{array}{l}\text { 25\% (moderate/severe } \\
\text { exacerbations) }\end{array}$ & $\begin{array}{l}0.092 \mathrm{~L}(0.075-0.108) \\
P<0.001^{\mathrm{a}}\end{array}$ & $\begin{array}{l}-3.1(-4.1 \text { to }-2.1) \\
P<0.001^{\text {b }}\end{array}$ & \multirow{2}{*}{$\begin{array}{l}\text { FSC } 50 / 500: 19.6 \%^{\mathrm{c}} \\
\text { FP } 500: 18.3 \%^{\mathrm{c}} \\
\text { SAL } 50: 13.3 \% \\
\text { PL: } 12.3 \%\end{array}$} \\
\hline 3 years duration (14) & $\begin{array}{l}\text { SFC } 50 / 250 \text { vs FC } 250 \\
\text { SFC } 50 / 250 \text { vs SAL } 50 \\
\text { FP } 250 \text { vs PL } \\
\text { SAL } 50 \text { vs PL }\end{array}$ & $\begin{array}{l}9 \% \text { (moderate/severe } \\
\text { exacerbations) } \\
12 \% \text { (moderate/severe } \\
\text { exacerbations) } \\
18 \% \text { (moderate/severe } \\
\text { exacerbations) } \\
\text { 15\% (moderate/severe } \\
\text { exacerbations) }\end{array}$ & $\begin{array}{l}0.044 \mathrm{~L}(0.028-0.061) \\
P<0.001^{\mathrm{a}} \\
0.050 \mathrm{~L}(0.034-0.067) \\
P<0.001^{\mathrm{a}} \\
0.047 \mathrm{~L}(0.031-0.064) \\
P<0.001^{\mathrm{a}} \\
0.042 \mathrm{~L}(0.025-0.058) \\
P<0.001^{\mathrm{a}}\end{array}$ & $\begin{array}{l}-1.2(-2.1 \text { to }-0.2) \\
P<0.02^{\mathrm{b}} \\
-2.2(-3.1 \text { to }-1.2) \\
P<0.001^{\mathrm{b}} \\
-2.0(-2.9 \text { to }-1.0) \\
P<0.001^{\mathrm{b}} \\
-1.0(-2.0 \text { to } 0) \\
P<0.06^{\mathrm{b}}\end{array}$ & \\
\hline $\begin{array}{l}\text { Calverley 2003, } \\
1 \text { year duration (15) }\end{array}$ & $\begin{array}{l}\text { BF } 320 / 9 \text { vs PL } \\
\text { BF } 320 / 9 \text { vs B } 320 \\
\text { BF } 320 / 9 \text { vs F } 9\end{array}$ & $\begin{array}{l}23.6 \% \\
25.5 \% \\
13.6 \%\end{array}$ & $\begin{array}{l}14 \% P<0.001^{\mathrm{d}} \\
11 \% P<0.001^{\mathrm{d}} \\
5 \% P=0.002^{\mathrm{d}}\end{array}$ & $\begin{array}{l}\text { Total score of active } \\
\text { treatment } \\
\text { versus placebo } \\
\text { (differences at } \\
12 \text { months): } \\
\text { BF } 320 / 9 \text { vs PL: }-7.5 \\
\text { BF } 320 \text { vs PL: }-3 \\
\text { F } 9 \text { vs PL: }-4.1\end{array}$ & $\begin{array}{l}\text { BF } 320 / 9: 3 \% \\
\text { B: } 400: 2 \% \\
\text { F } 9: 3 \% \\
\text { PL: } 1 \%\end{array}$ \\
\hline $\begin{array}{l}\text { Szafranski } 2003, \\
1 \text { year duration }\end{array}$ & $\begin{array}{l}\text { BF } 320 / 9 \text { vs PL } \\
\text { BF } 320 / 9 \text { vs B } 320 \\
\text { BF } 320 / 9 \text { vs F } 9\end{array}$ & $\begin{array}{l}24 \%(1.9-41.4) \\
P=0.035^{\mathrm{e}} \\
11 \%(-15.9-31.8 \\
P=0.385)^{\mathrm{e}} \\
23 \%(0.8-40.1 \\
P=0.043)^{\mathrm{e}}\end{array}$ & $\begin{array}{l}15 \%(11.0-19.1) \\
P<0.001^{\mathrm{e}} \\
9 \%(5.4-13.1) \\
P<0.001^{\mathrm{e}} \\
1 \%(-2.2-4.9) \\
P=0.487^{\mathrm{e}}\end{array}$ & $\begin{array}{l}\text { Mean reductions in } \\
\text { total score at } \\
12 \text { months from } \\
\text { baseline } \\
\text { BF } 320 / 9:-3.9 \\
P=0.009 \\
\text { BF } 320: 1.9 \\
\text { F } 9:-3.6 \\
\text { PL: }-0.03\end{array}$ & No data \\
\hline
\end{tabular}

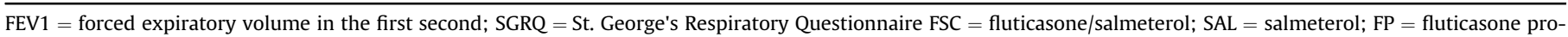
pionate; $\mathrm{BF}=$ budesonide/formoterol; $\mathrm{B}=$ budesonide; $\mathrm{F}=$ formoterol; $\mathrm{PL}=$ placebo.

a Difference in adjusted mean change in post-bronchodilator FEV1 averaged over the study time, $(95 \% \mathrm{CI}), P$ value.

b Difference in adjusted mean change in SGRQ score averaged over the study time, $(95 \% \mathrm{CI}), P$ value.

${ }^{c} P<0.001$ for the comparisons between the group receiving salmeterol plus fluticasone propionate and the placebo and between fluticasone group and the placebo group.

d Difference between different group of treatment in the variation of FEV1 from the improvement seen during the run -in period.

e Increase\%, (95\% CI), $P$ value. 


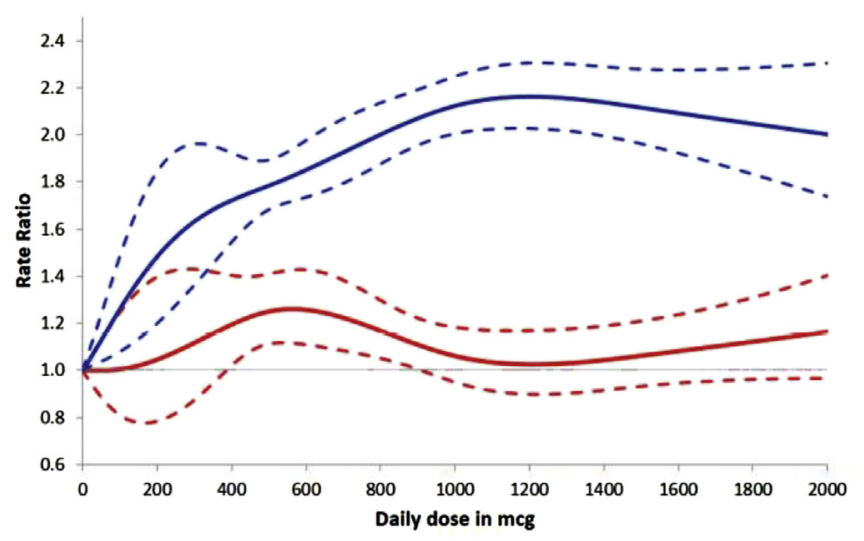

Fig. 1. Dose-dependent risk of pneumonia in patients with COPD treated with fluticasone (blue) or budesonide (red). Dashed lines represent 95\% CIs; doses are in $\mu$ g, measured in fluticasone equivalents. (reproduced with permission from Suissa et al., [32]). (For interpretation of the references to colour in this figure legend, the reader is referred to the web version of this article.)

inhibiting LPS-induced cytokine release from human alveolar macrophages.

\section{Final considerations}

ICS are important drugs for managing asthma and COPD. They are recommended for patients with COPD who have severe airflow limitation and/or frequent exacerbations, in combination with LABA [3]. However, individual ICS differ with respect to several pharmacologic properties, which may lead to different clinical effects. Regarding efficacy, fluticasone and budesonide appear to be equally effective when used alone or in combination with LABA in patients with COPD, although the majority of studies employed higher dosages of fluticasone. Budesonide has several favourable pharmacologic features, and in COPD the budesonide/formoterol combination is at least as effective as higher doses of fluticasone/ salmeterol combination. On the other hand, budesonide is associated with a lower risk of pneumonia and severe pneumonia, related to the different doses administered and the different pharmacologic profiles of these two ICS.

Therefore, a comprehensive evaluation of the risk/benefit ratio should be made when deciding on the type of ICS/LABA combination to recommend for patients with COPD.

\section{Acknowledgements}

English language editing and styling assistance was provided by Edra LSWR, Elsevier, and funded by AstraZeneca.

\section{References}

[1] Barnes PJ, Pedersen S, Busse WW. Efficacy and safety of inhaled corticosteroids. New developments. Am J Respir Crit Care Med 1998 Mar;157(3 Pt 2): $\mathrm{S} 1-53$.

[2] Global strategy for asthma management and prevention. www.ginasthma.org Update 2014.

[3] Global initiative for chronic obsructive lung disease. www.goldcopd.org Update 2011.

[4] Gibson PG, Simpson JL. The overlap syndrome of asthma and COPD: what are its features and how important is it? Thorax 2009 Aug;64(8):728-735S.

[5] Chung KF, Barnes PJ, editors. Pharmacology of the respiratory tract: experimental and clinical research. NewYork: Dekker; 1994.

[6] Raissy HH, Kelly HW, Harkins M, Szefler SJ. Inhaled corticosteroids in lung diseases. Am J Respir Crit Care Med 2013 Apr 15;187(8):798-803.

[7] Kelly HW. Comparison of inhaled corticosteroids: an update. Ann Pharmacother 2009;43:519-27.
[8] Derendorf H, Nave R, Drollman A, Cerasoli F, Wurst W. Relevance of pharmacokinetics and pharmacodynamics of inhaled corticosteroids to asthma. Eur Respir J 2006;28:1042-50.

[9] Rossi GA, Cerasoli F, Cazzola M. Safety of inhaled corticosteroids: room for improvement. Pulm Pharmacol Ther 2007;20:23-35.

[10] Dalby C, Polanowski T, Larsson T, Borgström L, Edsbäcker S, Harrison TW. The bioavailability and airway clearance of the steroid component of budesonide/ formoterol and salmeterol/fluticasone after inhaled administration in patients with COPD and healthy subjects: a randomized controlled trial. Respir Res 2009 Oct 31;10. $104 \mathrm{y}$

[11] Long F, Wang Y, Qi HH, Zhou X, Jin XQ. Rapid non-genomic effects of glucocorticoids on oxidative stress in a guinea pig model of asthma. Respirology 2008 Mar;13(2):227-32.

[12] Paggiaro PL, Dente FL, Morelli MC, Bancalari L, Di Franco A, Giannini D, et al. Postallergeninhaledbudesonidereduces late asthmaticresponse and inhibits the associatedincrease of airwayresponsiveness to methacholine in asthmatics. Am J Respir Crit Care Med 1994 Jun;149(6):1447-51.

[13] Lasserson TJ, Cates CJ, Ferrara G, Casali L. Combination fluticasone and salmeterol versus fixed dose combination budesonide and formoterol for chronic asthma in adults and children. Cochrane Database Syst Rev 2008 Jul 16;3: CD004106.

[14] Kuna P, Peters MJ, Manjra AI, Jorup C, Naya IP, Martínez-Jimenez NE, et al. Effect of budesonide/formoterol maintenance and reliever therapy on asthma exacerbations. Int J Clin Pract 2007 May;61(5):725-36.

[15] Bousquet J, Boulet LP, Peters MJ, Magnusen H, Quiralte J, Martinez-Aguilar NE, et al. Budesonide/formoterol for maintenance and relief in uncontrolled asthma vs. high-dose salmeterol/fluticasone. Respir Med 2007;101(12): 2437-46.

[16] Calverley P, Pauwels R, Vestbo J, Jones P, Pride N, Gulsvik A, et al., TRial of Inhaled STeroidsANd long-acting beta2 agonists study group. Combined salmeterol and fluticasone in the treatment of chronic obstructive pulmonary disease: a randomised controlled trial. Lancet 2003 Feb 8;361(9356):449-56.

[17] Calverley PM, Anderson JA, Celli B, Ferguson GT, Jenkins C, Jones PW, et al., TORCH investigators. Salmeterol and fluticasone propionate and survival in chronic obstructive pulmonary disease. N Engl J Med 2007 Feb 22;356(8): 775-89.

[18] Calverley PM, Boonsawat W, Cseke Z, Zhong N, Peterson S, Olsson H. Maintenance therapy with budesonide and formoterol in chronic obstructive pulmonary disease. Eur Respir J 2003 Dec;22(6):912-9.

[19] Szafranski W, Cukier A, Ramirez A, Menga G, Sansores R, Nahabedian S, et al. Efficacy and safety of budesonide/formoterol in the management of chronic obstructive pulmonary disease. Eur Respir J 2003 Jan;21(1):74-81.

[20] Lasserson TJ, Ferrara G, Casali L. Combination fluticasone and salmeterol versus fixed dose combination budesonide and formoterol for chronic asthma in adults and children. Cochrane Database Syst Rev 2011 Dec 7:12:CD004106.

[21] Blais L, Forget A, Ramachandran S. Relative effectiveness of budesonide/formoterol and fluticasone propionate/salmeterol in a 1-year, population-based, matched cohort study of patients with chronic obstructive pulmonary disease (COPD): effect on COPD-related exacerbations, emergency department visits and hospitalizations, medication utilization, and treatment adherence. ClinTher 2010 Jul;32(7):1320-8.

[22] Larsson K, Janson C, Lisspers K, Jorgensen L, Stratelis G, Telg G, et al. Combination of budesonide/formoterol more effective than fluticasone/salmeterol in preventing exacerbations in chronic obstructive pulmonary disease: the PATHOS study. J Intern Med 2013:273:584-94.

[23] Janson C, Larsson K, Lisspers KH, Stallberg B, Stratelis G, Goike H, et al. Pneumonia and pneumonia related mortality in patients with COPD treated with fixed combinations of inhaled corticosteroids and long acting b2 agonist: observational matched cohort study (PATHOS). Br Med J 2013;346:f3306.

[24] Agustí A, de Teresa L, De Backer W, Zvarich MT, Locantore N, Barnes N, et al. A comparison of the efficacy and safety of once-daily fluticasone furoate vilanterol with twice-daily fluticasone propionate/salmeterol in moderate to very severe COPD. Eur Respir J 2014 Mar;43(3):763-72.

[25] Dransfield MT, Feldman G, Korenblat P, LaForce CF, Locantore N, Pistolesi M, et al. Efficacy and safety of once-daily fluticasone furoate/vilanterol (100/25 $\mathrm{mcg}$ ) versus twice-daily fluticasone propionate/salmeterol $(250 / 50 \mathrm{mcg})$ in COPD patients. Respir Med 2014 Aug;108(8):1171-9.

[26] Dransfield MT, Bourbeau J, Jones PW, Hanania NA, Mahler DA, Vestbo J, et al. Once-daily inhaled fluticasone furoate and vilanterol versus vilanterol only for prevention of exacerbations of COPD: two replicate double-blind, parallelgroup, randomised controlled trials. Lancet Respir Med 2013 May;1(3): 210-23.

[27] Wedzicha JA, Singh D, Vestbo J, Paggiaro PL, Jones PW, Bonnet-Gonod F, et al., FORWARD Investigators. Extrafine beclomethasone/formoterol in severe COPD patients with history of exacerbations. Respir Med 2014 Aug;108(8): 1153-62.

[28] Ernst P, Suissa S. Systemic effects of inhaled corticosteroids. Curr Opin Pulm Med 2012 Jan;18(1):85-9.

[29] Loke YK, Cavallazzi R, Singh S. Risk of fractures with inhaled corticosteroids in COPD: systematic review and meta-analysis of randomised controlled trials and observational studies. Thorax 2011 Aug;66(8):699-708.

[30] Mak VH, Melchor R, Spiro SG. Easy bruising as a side-effect of inhaled corticosteroids. Eur Respir J 1992 Oct:5(9):1068-74.

[31] Pauwels RA, Löfdahl CG, Laitinen LA, Schouten JP, Postma DS, Pride NB, et al. Long-term treatment with inhaled budesonide in persons with mild chronic 
obstructive pulmonary disease who continue smoking. European respiratory society study on chronic obstructive pulmonary disease. N Engl J Med 1999 Jun 24;340(25):1948-53.

[32] O'Byrne PM, Pedersen S, Carlsson LG, Radner F, Thorén A, Peterson S, et al. Risks of pneumonia in patients with asthma taking inhaled corticosteroids. Am J Respir Crit Care Med 2011 Mar 1;183(5):589-95.

[33] Crim C, Calverley PM, Anderson JA, Celli B, Ferguson GT, Jenkins C, et al. Pneumonia risk in COPD patients receiving inhaled corticosteroids alone or in combination: TORCH study results. Eur Respir J 2009 Sep;34(3): $641-7$.

[34] Jenkins CR, Jones PW, Calverley PM, Celli B, Anderson JA, Ferguson GT, et al. Efficacy of salmeterol/fluticasone propionate by GOLD stage of chronic obstructive pulmonary disease: analysis from the randomised, placebocontrolled TORCH study. Respir Res 2009 Jun 30;10:59.

[35] Wedzicha JA, Calverley PM, Seemungal TA, Hagan G, Ansari Z, Stockley RA, INSPIRE Investigators. The prevention of chronic obstructive pulmonary disease exacerbations by salmeterol/fluticasone propionate or tiotropium bromide. Am J Respir Crit Care Med 2008 Jan 1;177(1):19-26.

[36] Kardos P, Wencker M, Glaab T, Vogelmeier C. Impact of salmeterol/fluticasone propionate versus salmeterol on exacerbations in severe chronic obstructive pulmonary disease. Am J Respir Crit Care Med 2007 Jan $15 ; 175(2): 144-9$.
[37] Sin DD, Tashkin D, Zhang X, Radner F, Sjöbring U, Thorén A, et al. Budesonide and the risk of pneumonia: a meta-analysis of individual patient data. Lancet 2009 Aug 29;374(9691):712-9.

[38] Singh S, Loke YK. Risk of pneumonia associated with long-term use of inhaled corticosteroids in chronic obstructive pulmonary disease: a critical review and update. Curr Opin Pulm Med 2010 Mar;16(2):118-22.

[39] Suissa S, Patenaude V, Lapi F, Ernst P. Inhaled corticosteroids in COPD and the risk of serious pneumonia. Thorax 2013 Nov;68(11):1029-36.

[40] Allen A, Bareille PJ, Rousell VM. Fluticasone furoate, a novel inhaled corticosteroid, demonstrates prolonged lung absorption kinetics in man compared with inhaled fluticasone propionate. Clin Pharmacokinet 2013 Jan;52(1): $37-42$.

[41] Calverley PM, Stockley RA, Seemungal TA, Hagan G, Willits LR, Riley JH, et al, Investigating New Standards for Prophylaxis in Reduction of Exacerbations (INSPIRE) Investigators. Reported pneumonia in patients with COPD: findings from the INSPIRE study. Chest 2011 Mar;139(3):505-12.

[42] Patterson CM, Morrison RL, D'Souza A, Teng XS, Happel KI. Inhaled fluticasone propionate impairs pulmonary clearance of klebsiellapneumoniae in mice. Respir Res 2012 May 31;13:40.

[43] Ek A, Larsson K, Siljerud S, Palmberg L. Fluticasone and budesonide inhibit cytokine release in human lung epithelial cells and alveolar macrophages. Allergy 1999 Jul;54(7):691-9. 